\title{
Is calcitonin an active hormone in the onset and prevention of hypocalcemia in dairy cattle?
}

\author{
E. M. Rodríguez, ${ }^{*}$ A. Bach, ${ }^{*} \dagger$ M. Devant, ${ }^{*}$ and A. Aris ${ }^{* 1}$ \\ *Department of Ruminant Production, Institut de Recerca i Tecnologia Agroalimentàries (IRTA), Torre Marimon, 08140 Caldes de Montbui, \\ Barcelona, Spain \\ †Institució Catalana de Recerca i Estudis Avançats (ICREA), 08010 Barcelona, Spain
}

\section{ABSTRACT}

The objective of this study was to assess the potential importance of calcitonin (CALC) in the onset of subclinical hypocalcemia (experiment 1) and in the physiological mechanisms underlying the prevention of bovine hypocalcemia under metabolic acidosis (experiments 2 and 3 ). In experiment 1, 15 Holstein cows naturally incurring subclinical hypocalcemia during the first $5 \mathrm{~d}$ postpartum were classified as low subclinical hypocalcemia (LSH) when blood $\mathrm{Ca}$ concentrations were between 7.5 and $8.5 \mathrm{mg} / \mathrm{dL}$, or as high subclinical hypocalcemia (HSH) when blood Ca concentrations were between 6.0 and $7.6 \mathrm{mg} / \mathrm{dL}$. Blood samples were taken daily from $\mathrm{d}-5$ to 5 relative to parturition to determine concentrations of parathyroid hormone (PTH), CALC, and 1,25(OH $)_{2} \mathrm{D}_{3}$. In experiment 2, 24 Holstein bulls (497 $\pm 69 \mathrm{~kg}$ of body weight and $342 \pm 10.5 \mathrm{~d}$ of age) were assigned to 2 treatments (metabolic acidosis or control). Metabolic acidosis was induced by an oral administration of ammonium chloride $(2.5 \mathrm{mEq} / \mathrm{d})$ during $10 \mathrm{~d}$, and animals were slaughtered thereafter. Blood samples were collected before slaughter to determine CALC, PTH, $1,25(\mathrm{OH})_{2} \mathrm{D}_{3}$, and samples of urine, kidney, parathyroid, and thyroid glands were obtained immediately after slaughter to determine expression of several genes in these tissues. Last, in experiment 3, we tested the activity of CALC under metabolic acidosis in vitro using breast cancer cell (T47D) cultures. Although PTH tended to be greater in HSH than in $\mathrm{LSH}$, the levels of $1,25(\mathrm{OH})_{2} \mathrm{D}_{3}$ were lower in $\mathrm{HSH}$ cows (experiment 1). Blood CALC concentration was not affected by the severity of subclinical hypocalcemia, but it was influenced by days from calving (experiment 1). The expression of PTH receptor (PTHR) in the kidney was increased under metabolic acidosis (experiment 2). Furthermore, the activity of CALC was impaired

Received August 8, 2015.

Accepted December 20, 2015.

${ }^{1}$ Corresponding author: anna.aris@irta.cat under acidic blood $\mathrm{pH}$ (experiment 3). In conclusion, the CALC rise in HSH cows after calving impaired the recovery of blood Ca concentrations because the PTHR response was not sufficient to activate $1,25(\mathrm{OH})_{2} \mathrm{D}_{3}$ and compensate for the CALC effect. Metabolic acidosis prevents hypocalcemia because the expression of PTHR is upregulated in the kidney, resulting in an increased PTH activity and a subsequent increase in $1,25(\mathrm{OH})_{2} \mathrm{D}_{3}$ serum concentrations. Moreover, an impairment of CALC activity at low $\mathrm{pH}$ enhances the hypercalcemic role of PTH.

Key words: calcitonin, hypocalcemia, metabolic acidosis, parathyroid hormone, $1,25(\mathrm{OH})_{2} \mathrm{D}_{3}$

\section{INTRODUCTION}

Parturient paresis is a common disease following calving in dairy cattle resulting from an inability of homeostatic mechanisms to regulate calcemia during a high demand for Ca when the lactating period begins. Hypocalcemia appears not only in clinical cases, but also in a subclinical form in $45 \%$ of cows. In both clinical and subclinical cases, the longevity and productivity of the cow are impaired (Goff, 2008; Murray et al., 2008), resulting in important economic losses for the dairy cattle industry. Under physiological conditions, the actions of calcitonin (CALC), parathyroid hormone (PTH), and $1,25(\mathrm{OH})_{2} \mathrm{D}_{3}$ control blood $\mathrm{Ca}$ concentrations. A decrease in blood Ca triggers the parathyroid gland to secrete PTH, which increases renal Ca reabsorption and induces the expression of 1- $\alpha$-hydroxylase in the kidney, responsible for producing $1,25(\mathrm{OH})_{2} \mathrm{D}_{3}$ (Wasserman and Fullmer, 1995). One of the most important effects of $1,25(\mathrm{OH})_{2} \mathrm{D}_{3}$ is to stimulate $\mathrm{Ca}$ absorption through the active transport across intestinal epithelial cells (Pérez et al., 2008). In addition, $1,25(\mathrm{OH})_{2} \mathrm{D}_{3}$ stimulates, in conjunction with $\mathrm{PTH}$, osteoclastic resorption activity of bone Ca (Horst et al., 2003). By contrast, CALC inhibits the resorption of bone Ca and increases urinary Ca loss to lower blood Ca concentration (Murray et al., 2008). Blood CALC concentrations increase in response 
to hypercalcemia (Austin and Heath, 1981; Findlay and Sexton, 2004) and studies with nonruminant animals also demonstrate an increase of CALC in response (or even in advance) to feed intake (Roos et al., 1980).

Thus far, no consensus exists about the triggering hormonal cause of the sudden drop of blood Ca. It is known that PTH and $1,25(\mathrm{OH})_{2} \mathrm{D}_{3}$ increase after a decrease in blood Ca around parturition (Wasserman and Fullmer, 1995). Because cow hypocalcemia is a disease related to low levels of $\mathrm{Ca}$ in blood, it could be argued that CALC may be involved in the onset of this affliction. However, evidence supporting a role of CALC in hypocalcemia in the cow is inconsistent. Capen and Young (1967) first proposed an etiological role of CALC in the incidence of parturient paresis. They found diminished CALC content in thyroid glands of cows with parturient paresis and suggested that an abrupt release of CALC near parturition may be related to the development of hypocalcemia. Barlet (1967) induced hypocalcemia in young and mature cows by intravenous administration of porcine CALC and also concluded that CALC release contributed to hypocalcemia or parturient paresis. In contrast, Mayer et al. (1975) suggested that the development of hypocalcemia at parturition may be associated with a diminished prepartal secretion of CALC. Similarly, Hollis et al. (1981) did not observe changes in blood CALC concentration along the periparturient period, but found that paretic animals had lower blood concentrations of CALC than normocalcemic animals. Last, Shappell et al. (1987) detected fluctuations in serum CALC between parturition and the fifth day postpartum in contrast to the response reported by Hollis et al. (1981). According to the Mayer et al. (1975) and Hollis et al. (1981) experiments, cows with normal or subclinical concentrations of blood Ca showed the highest peak of CALC at postpartum, whereas the lowest concentrations of serum CALC were found in clinical hypocalcemic cows.

Conversely, the diet of the cows before parturition may be involved in the incidence of periparturient paresis and hypocalcemia. Most prepartal diets based on forages are high in cations, such as $\mathrm{Na}$ and especially K. These diets may induce metabolic alkalosis and promote hypocalcemia because renal production of $1,25(\mathrm{OH})_{2} \mathrm{D}_{3}$ and osteoclastic bone resorption are decreased in contrast to anionic diets (Goff et al., 2008). Hence, the induction of metabolic acidosis through the supplementation of anionic salts creates a negative metabolic balance of $\mathrm{Ca}$ and prevents hypocalcemia at calving (Goff and Horst, 1998; Goff, 2008). Understanding the mechanisms that prevent a decrease in blood Ca concentrations at calving could also help to elucidate the key factors involved in the onset of hypocalcemia and to assess whether CALC has a relevant role in this process. However, the mechanism by which addition of anions to counteract cations in the diet of a cow enhances Ca homeostasis is not well understood. Leclerc and Block (1989), Goff et al. (1991), and Phillippo et al. (1994) provided indirect evidence that physiological functions stimulated by $\mathrm{PTH}$, such as bone resorption and production of $1,25(\mathrm{OH})_{2} \mathrm{D}_{3}$, were enhanced in cows fed diets containing added anions. Also, Goff et al. (2014) recently demonstrated that metabolic alkalosis reduces tissue sensitivity to PTH injections in comparison to cows under metabolic acidosis. Previous studies have also reported that metabolic acidosis increases the expression of CALC receptor (CALCR) in mouse osteoclasts (Biskobing and Fan, 2000) and upregulates the expression of PTH receptor (PTHR) along with PTH in rat osteoblast-like cells (Disthabanchong et al., 2002). Nevertheless, to our knowledge, no study has been conducted in cattle to assess the role of PTHR and CALCR in Ca homeostasis during metabolic acidosis. Furthermore, we know of no previous study that has evaluated whether CALC activity is affected under metabolic acidosis. The objective of the current study was to assess the role of CALC during subclinical hypocalcemia by comparing the hormonal levels at the onset of subclinical hypocalcemia and assessing the potential involvement of CALC in the physiological mechanisms participating in the prevention of bovine hypocalcemia under metabolic acidosis.

\section{MATERIALS AND METHODS}

\section{Experiment 1}

Animals and Sample Collection. Fifteen Holstein cows (mean $\pm \mathrm{SD} ; 4.01 \pm 1.1 \mathrm{yr}$ old, average lactation number $=1.6 \pm 0.7$, lactation length $=362 \pm 86.1 \mathrm{~d}$, average milk production $/ \mathrm{yr}=8,550 \pm 2,503.5 \mathrm{~kg}$, average $\mathrm{BW}$ of $674 \pm 22.8 \mathrm{~kg}$, and with a milk production peak in previous lactations above $30 \mathrm{~kg} / \mathrm{d}$ ) experiencing subclinical hypocalcemia (blood Ca between 6 and 8.5 $\mathrm{mg} / \mathrm{dL}$ ) during the first $5 \mathrm{~d}$ postpartum were classified in 2 groups depending on the levels of blood Ca. Eight animals were categorized as undergoing a low subclinical hypocalcemia (LSH), with blood Ca levels ranging between 7.5 and $8.5 \mathrm{mg} / \mathrm{dL}$, and 7 animals were classified as high subclinical hypocalcemia (HSH), with blood Ca levels between 6 and $7.4 \mathrm{mg} / \mathrm{dL}$. Blood samples were taken daily from $\mathrm{d}-5$ to 5 relative to parturition to perform subsequent hormonal analyses.

Blood Ca and Hormone Analysis. Plasma Ca was determined by atomic absorption spectrophotometry. Plasma PTH and $1,25(\mathrm{OH})_{2} \mathrm{D}_{3}$ concentrations were analyzed using commercial bovine ELISA kits from Immunotopics (San Clemente, CA) and Immunodiagnostic 
Systems (Boldon, UK), respectively. Plasma CALC was measured by a double-antibody RIA. Synthetic CALC was iodinated with $\left[{ }^{125} \mathrm{I}\right]$ Iodine (PerkinElmer, Waltham, MA) following the chloramine $\mathrm{T}$ method (Greenwood et al., 1963) and used as the tracer. The same synthetic CALC was used as the standard and to raise a polyclonal serum in rabbits. Two rabbits were inoculated subcutaneously with bovine CALC conjugated to ovalbumin in complete Freund's adjuvant. At 3, 6, and 9 wk after the first inoculation they received a booster injection with the same preparation, except that incomplete Freund's adjuvant was used. Exsanguination was performed 2 wk after the last booster injection and polyclonal serum was collected.

Before determining CALC using RIA, plasma samples were mixed with 1.5 volumes of acetone (SigmaAldrich, St. Louis, MO) and incubated on ice. After centrifugation at $4,700 \times g$ at $4^{\circ} \mathrm{C}$ for $10 \mathrm{~min}$, the liquid phase was dried up by a nitrogen stream and the wet material reconstituted with assay buffer $(0.25 \%$ bovine albumin; 0.1\% Triton X-100; $25 \mathrm{mM}$ EDTA; $50 \mathrm{mM}$ sodium phosphate; $\mathrm{pH}$ 7.4). All samples that were compared were run in the same assay to avoid interassay variability. The intra-assay coefficient of variation was $5.6 \%$.

\section{Experiment 2}

Animals, Treatments, and Sampling. Twentyfour Holstein bulls $(497 \pm 69 \mathrm{~kg}$ of BW and $342 \pm$ $10.5 \mathrm{~d}$ of age) were randomly distributed to 2 treatments: control or metabolic acidosis. Animals were randomly distributed in 6 identical covered pens $(12 \times 6$ $\mathrm{m})$ bedded with straw. In each pen, animals had access to a drinker and received ad libitum concentrate $(14.2 \%$ CP, $6.8 \%$ ether extract, $20.4 \%$ NDF, $5.1 \%$ ash in DM basis) and straw. The animals assigned to the metabolic acidosis treatment were given an oral drenching of $133 \mathrm{~g}$ of $\mathrm{NH}_{4} \mathrm{Cl}$ (Panreac, Castellar de Vallès, Spain) diluted in water twice a day (morning and evening) during the $10 \mathrm{~d}(2.5 \mathrm{Eq} / \mathrm{d})$ experiment. At d 10 from the onset of the study, animals were transported to the slaughterhouse. Samples of venous blood were obtained from the coccygeal vein before slaughter in vacutainer tubes containing sodium heparin (Becton Dickinson, Franklin Lakes, NJ). Blood pH was measured immediately after the extraction. Then, blood was centrifuged at $2,300 \times g$ at $4^{\circ} \mathrm{C}$ for 10 min and plasma immediately frozen for subsequent hormonal analysis. Parathyroid hormone concentrations were quantified in plasma by ELISA (Immunotopics, San Clemente, CA) and 1,25-dihydroxy vitamin D using an enzyme immunoassay kit from Immunodiagnostic systems following the manufacturer instructions. At the slaughterhouse $(3 \mathrm{~h}$ after blood sampling), urine was collected from the bladder immediately after animal euthanasia and urine $\mathrm{pH}$ was measured. Also, tissue samples of kidney (glomerular cortex region), parathyroid gland, and thyroid gland were collected and immediately preserved in RNAlater (Invitrogen, Carlsbad, CA) for subsequent gene expression analysis.

Gene Expression Analyses. Tissue samples from the kidney, parathyroid gland, and thyroid gland were homogenized before RNA extraction using a homogenizer (VDI 12; VWR, Radnor, PA). Messenger RNA was isolated with the use of Trizol (Invitrogen) and mRNA retrotranscribed to cDNA using iScript cDNA Synthesis Kit (Bio-Rad Laboratories, Hercules, CA). Specific bovine primers for $\beta$-actin (reference gene), PTH, PTHR, CALC, CALCR, and human CALCR genes (Table 1) were designed using the Quantprime software (Arvidsson et al., 2008). Quantitative realtime PCR was performed using IQ SYBR Green Supermix (Bio-Rad Laboratories) with the MyIQ RealTime detection system from Bio-Rad Laboratories. The PCR reactions were performed in triplicate and water was used as a negative control. The specificity of the amplification was evaluated by the single band identification at the expected molecular weight in $0.8 \%$ DNA agarose gels and a single peak in in melting curves. The efficiency of each pair of primers was calculated by amplifying serial 1:10 dilutions of each gene amplicon. A standard curve of cycle threshold (Ct) versus log concentration was plotted to measure efficiency, which was calculated using the formula $10^{(-1 / \text { slope })}$, with an acceptable range of 1.8 to 2.2. Gene expression levels were analyzed by the method of comparative critical threshold $\Delta \Delta \mathrm{Ct}$ (Livak and Schmittgen, 2001) using $\beta$-actin gene as a reference gene.

\section{Experiment 3}

Studies of CALC activity in acidosis were performed in cultures of T47D breast cancer cells purchased from the European Collection of Cell Cultures (Salisbury, UK). Cells were grown in DMEM (Invitrogen) supplemented with $10 \%$ fetal bovine serum (Invitrogen) and $100 \mathrm{~nm}$ of dexamethasone (Sigma-Aldrich), using 100 $\mu \mathrm{L}$ at a density of $10^{5}$ cells $/ \mathrm{mL}$ in 96 -well plates. Cells were incubated at different $\mathrm{pH}(7.1,7.2,7.3$, and 7.4) for $48 \mathrm{~h}$ at $37^{\circ} \mathrm{C}$ in a $5 \% \mathrm{CO}_{2}$ atmosphere. The $\mathrm{pH}$ of the medium was adjusted using $\mathrm{HCl}$ or $\mathrm{NaOH}$. After this period, cells were used in a CALC activity assay or lysed with Trizol (Invitrogen) to analyze the expression of CALCR by real-time PCR.

In the CALC activity assay, a final concentration of $40 \mathrm{n} M$ bovine CALC (synthesized in the Proteomics Department of the Universitat Pompeu Fabra, Barce- 
lona, Spain) was added to the wells for $90 \mathrm{~min}$. Then, cells were washed twice with PBS and lysed with 0.1 $M \mathrm{HCl}$ for $15 \mathrm{~min}$. The cell extracts were frozen and further analyzed for cyclic AMP, the second messenger of CALC, using a commercial ELISA kit (Enzo Life Sciences, Farmingdale, NY; Lamp et al., 1981).

\section{Statistical Analysis}

Data from experiment 1 were analyzed using a mixed-effects model with repeated measures; the model included treatment, time, and their 2-way interaction as fixed effects and animal as a random effect. Data were log- or root-transformed when necessary to achieve normal distributions.

Data from experiments 2 and 3 were analyzed using SAS (SAS Institute Inc., Cary, NC) with an ANOVA with treatment (control vs. metabolic acidosis) as main effect. Data were log-transformed or root-transformed when necessary to achieve normal distributions.

\section{RESULTS AND DISCUSSION}

To assess the role of CALC in the onset of hypocalcemia, the hormonal profile of cows incurring subclinical hypocalcemia were analyzed peripartum. Cows with blood Ca levels below the traditional threshold of $8.0 \mathrm{mg} / \mathrm{dL}$ were considered to have subclinical hypocalcemia. Recent research has indicated that this threshold should be raised to $8.59 \mathrm{mg} / \mathrm{dL}$, the level at which negative health effects actually become apparent (Martinez et al., 2012). In the present study, cows were classified within the range of 8.5 to $7.5 \mathrm{mg} / \mathrm{dL}$ of blood $\mathrm{Ca}$ as having LSH or as HSH when blood Ca was 7.4 to $6 \mathrm{mg} / \mathrm{dL}$. As expected, cows on HSH had lower $(P$ $<0.0001)$ Ca concentrations along the $5 \mathrm{~d}$ postpartum than before calving, whereas LSH cows only showed a moderate reduction $(P<0.0001)$ of blood $\mathrm{Ca}$ at calving (d 0) or at d 4 postcalving (Figure 1). Blood PTH concentration tended to differ $(P=0.09)$ between HSH and LSH cows, and they were greater $(P<0.0001)$ postpartum than before calving in both groups. The increase in blood PTH was maintained during $3 \mathrm{~d}$ postcalving in $\mathrm{HSH}$ animals, whereas it was sustained for at least $5 \mathrm{~d}$ in LSH animals (Figure 1). Interestingly, LSH cows had greater $(P<0.05)$ blood $1,25(\mathrm{OH})_{2} \mathrm{D}_{3}$ concentrations $(39.34 \pm 7.537 \mathrm{pmol} / \mathrm{L})$ than cows that were HSH $(20.11 \pm 6.98 \mathrm{pmol} / \mathrm{L})$ throughout the peripartum period ( -5 to $5 \mathrm{~d}$ from calving), and blood $1,25(\mathrm{OH})_{2} \mathrm{D}_{3}$ concentrations increased $(P<0.0001)$ during the postpartum in both groups. Hence, although blood PTH concentrations tended to be greater in $\mathrm{HSH}$ than in LSH cows, blood levels of $1,25(\mathrm{OH})_{2} \mathrm{D}_{3}$ were lower $(P<0.05)$ in HSH than in LSH cows (Figure 1). This finding supports that the production of $1,25(\mathrm{OH})_{2} \mathrm{D}_{3}$ is not only controlled by PTH through the regulation of 1- $\alpha$ hydroxylation of $1,25(\mathrm{OH})_{2} \mathrm{D}_{3}$, but also by the PTHR, as previously hypothesized by other authors (Phillippo et al., 1994; Goff et al., 2014). However, PTH was not able to stimulate the enzyme 1- $\alpha$-hydroxylase to produce $1,25(\mathrm{OH})_{2} \mathrm{D}_{3}$ with the same efficiency in HSH as in LSH cows, probably due to the amount or sensitivity of the PTHR.

Blood CALC was quantified by RIA. The validation of rabbit polyclonal antibody against CALC is shown in Figure 2. Overall, blood CALC concentration was not affected $(P=0.29)$ by the severity of subclinical hypocalcemia, but it was influenced by days from calving, as has been previously reported by Hollis et al. (1981) and Shappell et al. (1987), showing greater $(P<$ 0.0001 ) concentrations on $\mathrm{d} 1,2$, and 3 in $\mathrm{HSH}$ and on d 1 in LSH cows (Figure 1). However, an interaction $(P$ $<0.05)$ between the severity of subclinical hypocalcemia (HSH and LSH) and days since calving was noted (Figure 1). At calving (d 0) and on d 2 postpartum, HSH cows had 2.25- and 1.89-fold more blood CALC than LSH, respectively. According to Shappell et al. (1987), peak concentration of blood CALC appeared to coincide with or follow peaks in circulating PTH concentration, reflecting the feedback between the roles of

Table 1. Sequence of primer sequence for different genes and optimized quantitative PCR conditions

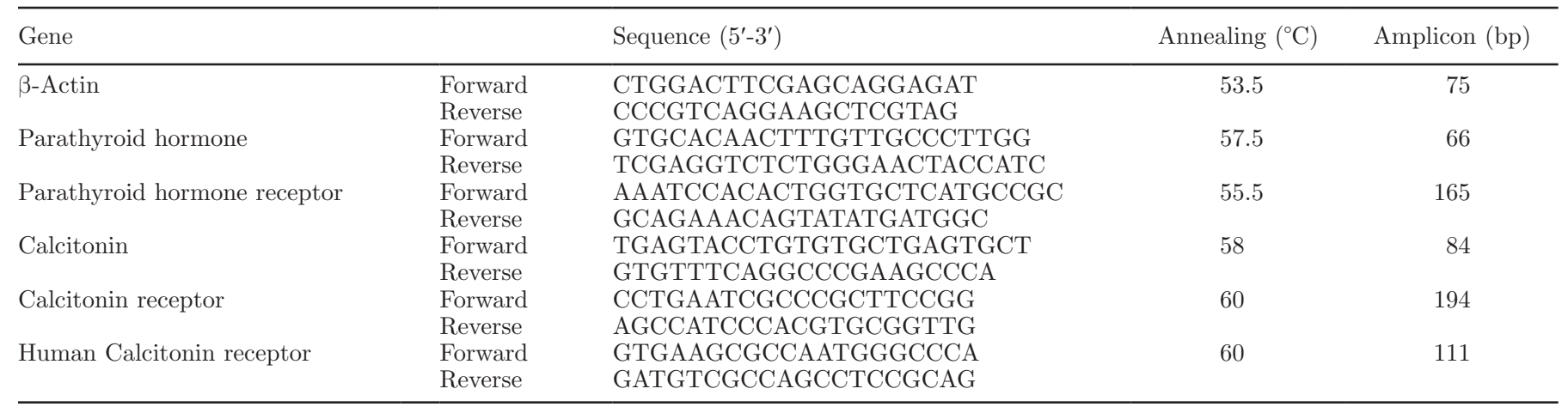




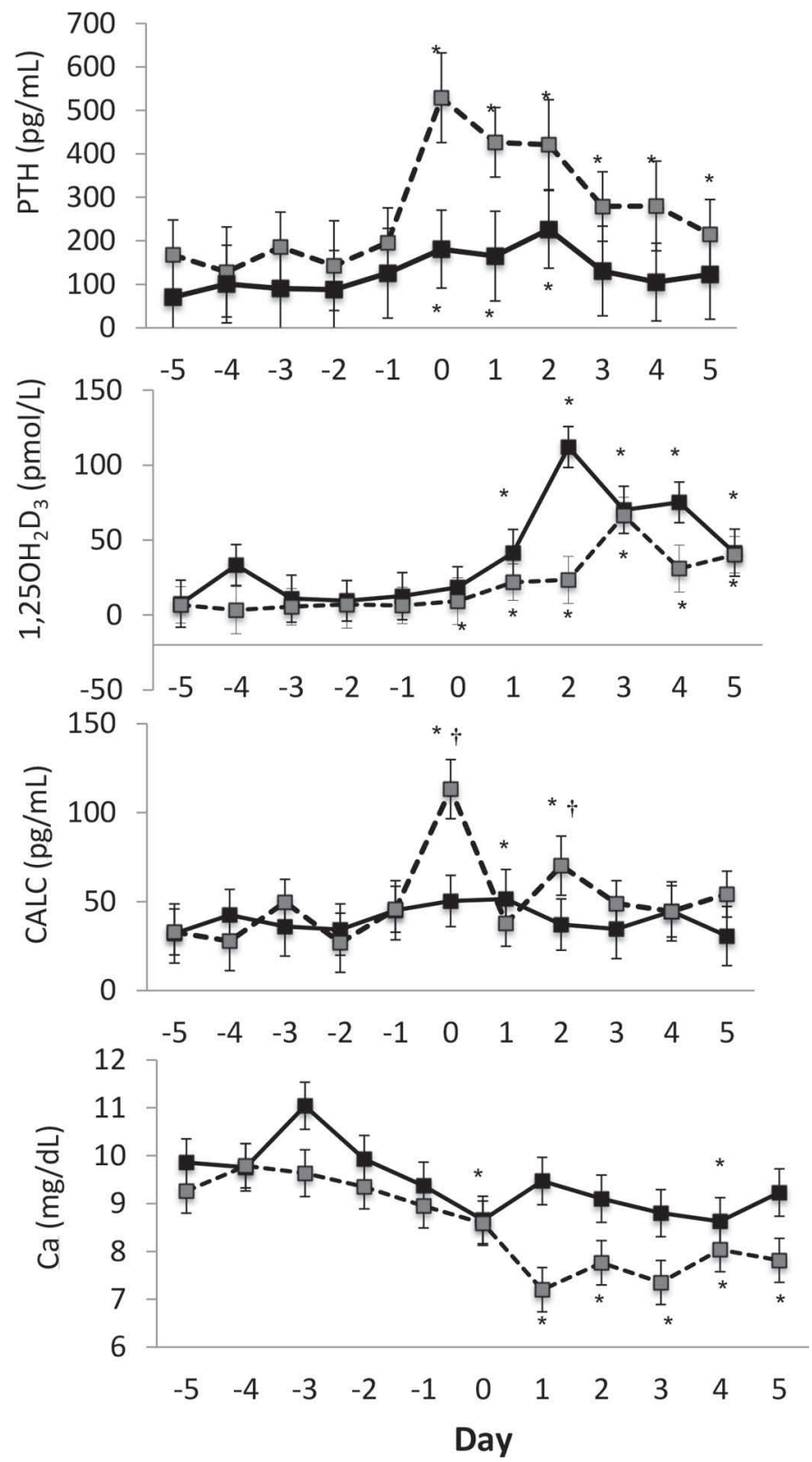

Figure 1. Profiles of blood parathyroid hormone (PTH), $1.25(\mathrm{OH})_{2} \mathrm{D}_{3}$, calcitonin (CALC), and calcium along the periparturient period ( -5 to 5 d relative to calving). Solid black lines correspond to cows classified as having low subclinical hypocalcemia (LSH) and dashed black lines correspond to cows classified as having high subclinical hypocalcemia (HSH). Asterisks $(*)$ indicate differences $(P<$ $0.05)$ regarding day $-5 \mathrm{~d}$ and crosses $(\dagger)$ depict differences $(P<0.05)$ between LSH and HSH groups. Error bars correspond to SEM.

these 2 hormones: PTH increasing resorption of bone, and CALC decreasing resorption and increasing urinary Ca excretion. Interestingly, in the study of Shappell et al. (1987), the animals had subclinical hypocalcemia (values $>6 \mathrm{mg} / \mathrm{dL}$ ) and the results of hormone concentrations were similar to the ones presented herein. However, Hollis et al. (1981) studied hormonal differ- ences between animals with clinical hypocalcemia $(<6$ $\mathrm{mg} / \mathrm{dL}$ ) and normocalcemic animals and did not detect feedback between PTH and CALC nor the CALC peak after calving, probably because the low concentration of Ca inhibited the synthesis of CALC. This fact should be taken into account in future studies, as it is possible that mechanisms involved in subclinical or clinical hypocalcemia are different and some preventive strategies that do not work for animals clinically affected could be effective in subclinical cases.

Overall, the results of our study suggest that, after calving, CALC appears to exert a feedback on PTH release when cows are suffering from subclinical hy-

a

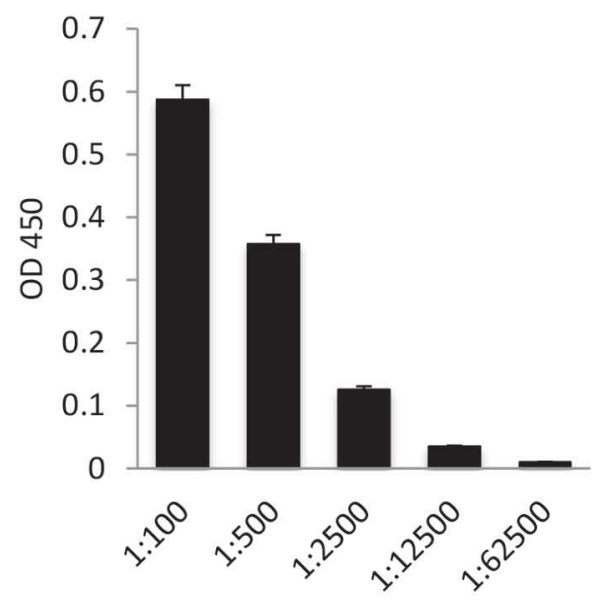

Anti-calcitonin dilution

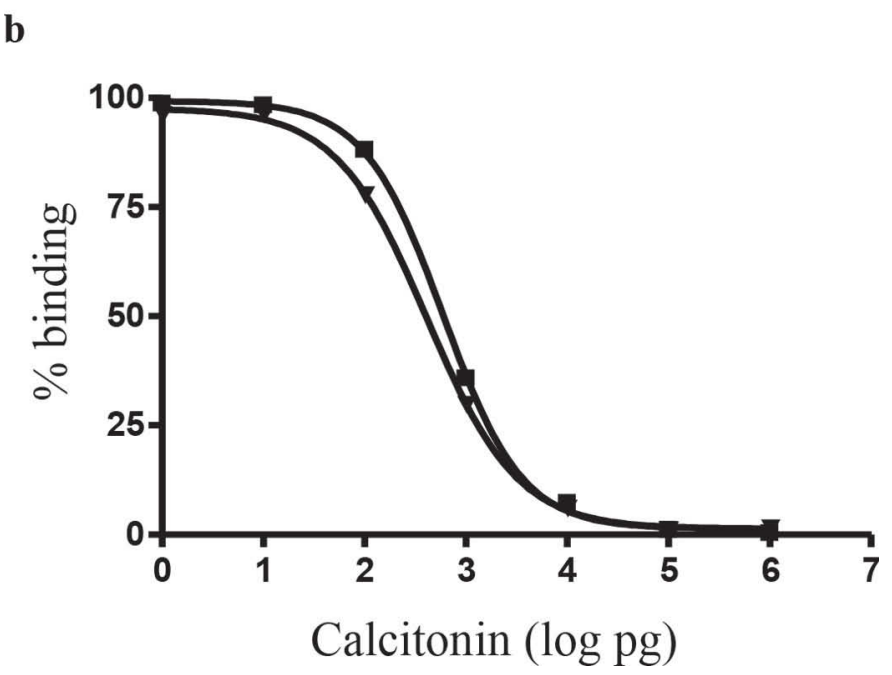

Figure 2. Performance of rabbit polyclonal sera against calcitonin. (a) Least squares means $( \pm \mathrm{SE})$ of optical density (OD) at $450 \mathrm{~nm}$ obtained with different dilutions of polyclonal rabbit serum against calcitonin in an indirect ELISA. (b) Percentage of binding to iodinated calcitonin in RIA assay using a 1:2,000 (squares) and 1:5,000 (triangles) dilutions of rabbit polyclonal. 
Table 2. Blood and urine $\mathrm{pH}$, gene expression (by $\Delta \Delta \mathrm{Ct}$ method, wher $\mathrm{Ct}=$ cycle threshold), and blood concentration of different parameters of tissues taken from bulls receiving anion drenches (anionic) or nothing (control)

\begin{tabular}{lcccc}
\hline & \multicolumn{2}{c}{ Treatment } & & \\
\cline { 2 - 3 } Item & Control & Anionic & \multirow{2}{*}{ SEM } & P-value \\
\hline pH & $7.64^{*}$ & $7.57^{*}$ & 0.015 & 0.003 \\
Blood & $7.38^{*}$ & $5.95^{*}$ & 0.135 & $<.0001$ \\
Urine & & & & \\
Gene expression, $\Delta \Delta \mathrm{Ct}$ & 122.2 & 82.9 & 37.89 & 0.20 \\
Calcitonin (thyroid) & 0.0062 & 0.0067 & 0.00257 & 0.48 \\
Calcitonin receptor (thyroid) & 0.00073 & 0.00070 & 0.000328 & 0.77 \\
Calcitonin receptor (kidney) & 0.010 & 0.014 & 0.0064 & 0.64 \\
Parathyroid hormone (parathyroid) & 0.00144 & 0.00147 & 0.000322 & 0.94 \\
Parathyroid hormone receptor (parathyroid) & $0.069^{*}$ & $0.115^{*}$ & 0.0139 & 0.03 \\
Parathyroid hormone receptor (kidney) & & & & \\
Blood concentration & 207.7 & 213.5 & 27.36 & 0.88 \\
Parathyroid hormone, pg/mL & 455.1 & 603.9 & 68.73 & 0.14 \\
1,25(OH) ${ }_{2}$-vitamin $\mathrm{D}_{3}, \mathrm{pmol} / \mathrm{L}$ & & & & \\
\hline
\end{tabular}

pocalcemia. The CALC rise was highest in HSH cows because blood PTH concentrations were also greatest in the animals (Figure 1). Surprisingly, regardless of high blood PTH concentrations, the induction of $1,25(\mathrm{OH})_{2} \mathrm{D}_{3}$ was impaired in these animals, which combined with a CALC peak made it more difficult for HSH cows to recover from hypocalcemia.

A common practice in the field to prevent hypocalcemia in cows consists of inducing metabolic acidosis. With the results from experiment 1 in mind, a second experiment was conducted to further understand potential mechanisms behind $\mathrm{Ca}$ homeostasis. Experiment 2 focused on the CALC/CALCR and PTH/PTHR systems in kidney and thyroid or parathyroid glands in metabolic acidosis. In experiment 2 , supplementing diets with ammonium chloride led to a reduction in blood $(P<0.01)$ and urine $(P<0.001) \mathrm{pH}$ (Table 2$)$ in bulls receiving the metabolic acidosis treatment $(7.57$ \pm 0.015 and $5.95 \pm 0.135$, respectively) in comparison with the control group $(7.64 \pm 0.015$ and $7.38 \pm 0.135$, respectively). These data indicate that the strategy adopted to induce metabolic acidosis was successful.

No differences were found in the expression of PTH and CALC genes in the parathyroid gland or the thyroid gland (Table 2 and Figure 3). Moreover, serum PTH concentrations were not different between the 2 experimental groups (Table 2); serum concentrations of $1,25(\mathrm{OH})_{2} \mathrm{D}_{3}$ did not differ between treatments either. The expression of PTHR in the parathyroid gland was similar between groups (Table 2 and Figure 3 ), but the expression of PTHR in the kidney was greater $(P<$ $0.05)$ in the animals under metabolic acidosis than in the control ones (Table 2 and Figure 3). These results indicate that metabolic acidosis enhances the activity of PTH in cattle through an increase of the expression of its receptors in the kidney, potentially leading to an increased coupling of the hormone with its receptor and, as a consequence, a possible increased synthesis of $1,25(\mathrm{OH})_{2} \mathrm{D}_{3}$, which would ultimately trigger an hypercalcemic response. Despite the fact our experiment was carried out in bulls, the results allow us to formulate a hypothesis about important key factors modulating Ca homeostasis under conditions of metabolic acidosis. However, we could not exclude a possible different response in cows. It is important to stress that these results are in agreement with an in vitro study performed with rat osteoblast-like cells, where the number of PTH receptors increased under metabolic acidosis (Disthabanchong et al., 2002). In this context, a possible explanation for the impaired $1,25(\mathrm{OH})_{2} \mathrm{D}_{3}$ activa-

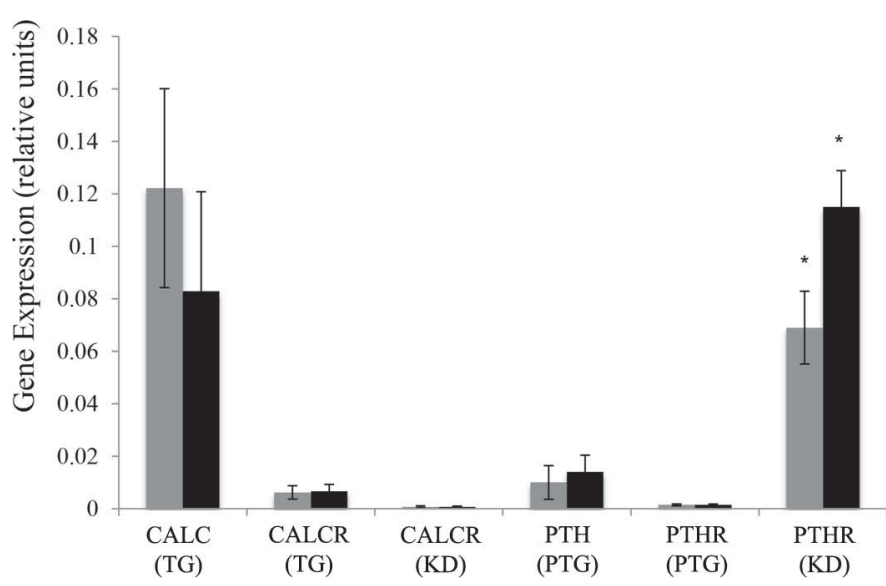

Figure 3. Gene expression analyses of calcitonin (CALC), calcitonin receptor (CALCR), parathyroid hormone (PTH), and parathyroid hormone receptor (PTHR) in kidney (KD), thyroid (TG), and parathyroid (PTG) glands from bulls given anion drenches (black bars) or nothing (gray bars). An asterisk $(*)$ depicts differences $(P<0.05)$ between groups. Results are expressed as the means of nontransformed data \pm SEM. 
tion in HSH cows during lactation (experiment 1) could be due to low levels of PTHR.

The role of CALC under metabolic acidosis has not been previously described, and the results of hormonal expression of the present study (Table 2 and Figure 3 ) only show a nonsignificant decline in CALC expression when metabolic acidosis was induced. To study the effect of acidosis on CALC activity, the gene expression of CALCR was also analyzed in both the thyroid gland and the kidney. Metabolic acidosis did not affect the gene expression of CALCR, either in the thyroid gland or in the kidney (Table 2 and Figure 3). However, we cannot discard a potential effect of metabolic acidosis on the CALCR in bone because this tissue was not evaluated herein. To assess whether the activity of CALC could be somehow affected by blood $\mathrm{pH}$, the in vitro experiment 3 was conducted with the cell line T47D that expresses CALCR (Goldring, 1997). Cells were incubated at different $\mathrm{pH}$ with bovine CALC and hormone activity was monitored through the synthesis of cyclic AMP produced after the binding of CALC with CALCR. The activity of CALC was greater at physiological $\mathrm{pH} 7.4$, and decreased as $\mathrm{pH}$ decreased (Figure 4). The synthesis of CALCR was also analyzed in T47D cells, but was not affected by $\mathrm{pH}$ (data not shown). These results demonstrate that CALC and PTHR could be key factors modulating Ca homeostasis. The decrease of CALC activity under acidosis would have a synergistic effect with the upregulation of the expression of PTHR and the consequent increase of PTH activity, leading to a final increase in blood Ca levels.

In conclusion, our study demonstrates that CALC has an important role in exacerbating the decrease in blood Ca levels at the onset of subclinical hypocalcemia. The basis of this negative effect of CALC resides in the

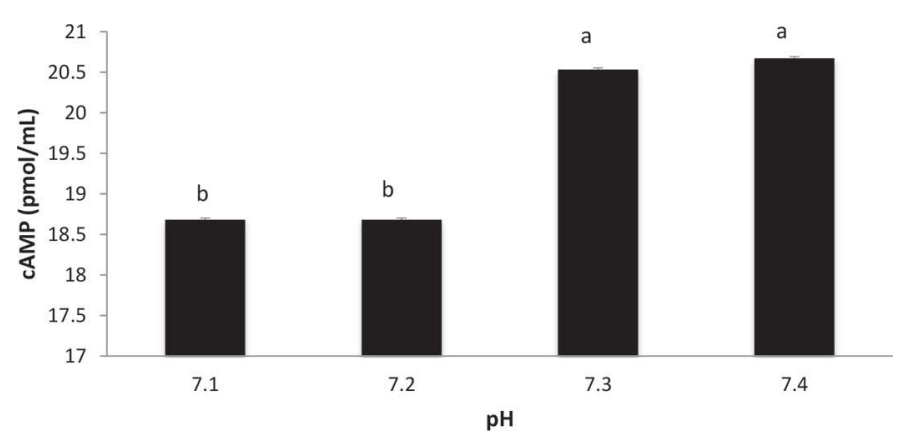

Figure 4. Ability of calcitonin (CALC) to elicit production of cyclic AMP (cAMP) by T47D breast cancer cells at different $\mathrm{pH}$ values. Different letters $(\mathrm{a}, \mathrm{b})$ depict differences $(P<0.05)$ between groups. Results are expressed as means of nontransformed data \pm SEM obtained from normalized data. delay between the PTH synthesis and the PTH effect that seems to be improperly controlled by unknown reasons in HSH cows. The results from this study indicate that under metabolic acidosis, an impairment of CALC activity in combination with an increase in the number of PTHR could improve Ca homeostasis. This demonstrates that the number of PTHR could be a key factor for Ca homeostasis, and we hypothesized that low levels of PTHR are responsible for an impaired $1,25(\mathrm{OH})_{2} \mathrm{D}_{3}$ activation that, in combination with a CALC rise, impaired $\mathrm{Ca}$ homeostasis in subclinical hypocalcemic cows.

\section{ACKNOWLEDGMENTS}

We thank the Instituto Nacional de Investigación y Tecnología Agraria y Alimentarias (Madrid, Spain) for the partial financial support of this project (RTA200900051-00-00). We also thank Ricard Martin and Daniel Sabrià (from the University of Girona, Girona, Spain) for their help with bull management.

\section{REFERENCES}

Arvidsson, S., M. Kwasniewski, D. M. Riano-Pachon, and B. Mueller-Roeber. 2008. QuantPrime-A flexible tool for reliable highthroughput primer design for quantitative PCR. BMC Bioinformatics 9:465-469.

Austin, L. A., and H. Heath 3rd.. 1981. Calcitonin: Physiology and pathophysiology. N. Engl. J. Med. 304:269-278.

Barlet, J. P. 1967. Induction experimentale d'un syndrome analogue a'la fievre vitulaire par administration de thyrocalcitonin a des vaches en cours de lactation. CR Acad. Sci. Ser. 265:1075-1078.

Biskobing, D. M., and D. Fan. 2000. Acid pH increases carbonic anhydrase ii and calcitonin receptor mRNA expression in mature osteoclasts. Calcif. Tissue Int. 67:178-183.

Capen, C. C., and D. M. Young. 1967. Thyrocalcitonin: Evidence for release in a spontaneous hypocalcemic disorder. Science 157:205206.

Disthabanchong, S., K. J. Martin, C. L. McConkeya, and E. A. Gonzalez. 2002. Metabolic acidosis up-regulates PTH/PTHrP receptors in UMR 106-01 osteoblast-like cells. Kidney Int. 62:1171-1177.

Findlay, D. M., and P. M. Sexton. 2004. Calcitonin. Growth Factors $22: 217-224$.

Goff, J. P. 2008. The monitoring, prevention, and treatment of milk fever and subclinical hypocalcemia in dairy cows. Vet. J. 176:50-57.

Goff, J. P., and R. L. Horst. 1998. Use of hydrochloric acid as a source of anions for prevention of milk fever. J. Dairy Sci. 81:2874-2880.

Goff, J. P., R. L. Horst, F. J. Mueller, J. K. Miller, G. A. Kiess, and H. H. Dowlen. 1991. Addition of chloride to a prepartal diet high in cations increases 1,25-dihydroxyvitamin D response to hypocalcemia preventing milk fever. J. Dairy Sci. 74:3863-3871.

Goff, J. P., A. Liesegang, and R. L. Horst. 2014. Diet-induced pseudohypoparathyroidism: A hypocalcemia and milk fever risk factor. J. Dairy Sci. 97:1520-1528.

Goldring, S. R. 1997. Molecular biology and regulation of the calcitonin receptor. J. Bone Miner. Metab. 15:51-58.

Greenwood, F. C., W. M. Hunter, and J. S. Glover. 1963. The preparation of ${ }^{131}$ I-labelled human growth hormone of high specific radioactivity. Biochem. J. 89:114-123.

Hollis, B. W., H. H. Draper, J. H. Burton, and R. J. Etches. 1981. A hormonal assessment of bovine parturient paresis: Evidence for a role of oestrogen. J. Endocrinol. 88:161-171. 
Horst, R. L., J. P. Goff, and T. A. Reinhardt. 2003. Role of vitamin D in calcium homeostasis and its use in prevention of bovine periparturient paresis. Acta Vet. Scand. Suppl. 97:35-50.

Lamp, S. J., D. M. Findlay, J. M. Moseley, and T. J. Martin. 1981. Calcitonin induction of a persistent activated state of adenylate cyclase in human breast cancer cells (T47D). J. Biol. Chem. 256:12269-12274.

Leclerc, H., and E. Block. 1989. Effects of reducing dietary cationanion balance for prepartum dairy cows with specific reference to hypocalcemic parturient paresis. Can. J. Anim. Sci. 69:411-417.

Livak, K. J., and T. D. Schmittgen. 2001. Analysis of relative gene expression data using real time quantitative PCR and the $2^{\Delta \Delta} \mathrm{C}(\mathrm{T})$. Methods 25:402-408.

Martinez, N., C. A. Risco, F. S. Lima, R. S. Bisinotto, L. F. Greco, E. S. Ribeiro, F. Maunsell, K. Galvão, and J. E. Santos. 2012. Evaluation of peripartal calcium status, energetic profile, and neutrophil function in dairy cows at low or high risk of developing uterine disease. J. Dairy Sci. 95:7158-7172.

Mayer, G. P., J. W. Blum, and L. J. Deftos. 1975. Diminished prepartal plasma calcitonin concentration on cows developing parturient hypocalcemia. Endocrinology 96:1478-1485.
Murray, R. D., J. E. Horsfield, W. D. McCormick, H. J. Williams, and D. Ward. 2008. Historical and current perspectives on the treatment, control and pathogenesis of milk fever in dairy cattle. Vet. Rec. 163:561-565.

Pérez, A. V., P. Gabriela, A. R. Carpentieri, M. A. Rivoira, M. E. Peralta, and N. G. Tolosa. 2008. Minireview on regulation of intestinal calcium absorption. Digestion 77:22-34.

Phillippo, M., G. W. Reid, and I. M. Nevison. 1994. Parturient hypocalcaemia in dairy cows: effects of dietary acidity on plasma minerals and calciotrophic hormones. Res. Vet. Sci. 56:303-309.

Roos, B. A., M. Yoon, S. V. Cutshaw, and D. N. Kalu. 1980. Calcium regulatory action of endogenous rat calcitonin demonstrated by passive immunization with calcitonin antibodies. Endocrinology 107:1320-1326.

Shappell, N. W., J. H. Herbein, L. J. Deftos, and R. J. Aiello. 1987. Effects of dietary calcium and age on parathyroid hormone, calcitonin and serum and milk minerals in the periparturient dairy cow. J. Nutr. 117:201-207.

Wasserman, R. H., and C. S. Fullmer. 1995. Vitamin D and calcium transport: speculations and hypotheses. J. Nutr. (Suppl.) 125:1971S-1979S 